Article

\title{
Immigrant Influencers on TikTok: Diverse Microcelebrity Profiles and Algorithmic (In)Visibility
}

\author{
Daniela Jaramillo-Dent ${ }^{1,2, *}$, Paloma Contreras-Pulido ${ }^{3}$, and Amor Pérez-Rodríguez ${ }^{1}$ \\ ${ }^{1}$ Department of Philology, University of Huelva, Spain \\ ${ }^{2}$ Department of Media and Communication, Erasmus University Rotterdam, The Netherlands \\ ${ }^{3}$ Department of Education, International University of La Rioja, Spain \\ * Corresponding author (daniela.jaramillo@pi.uhu.es)
}

Submitted: 28 July 2021 | Accepted: 30 September 2021 | Published: 24 February 2022

\begin{abstract}
Internet celebrity has become a phenomenon of great interest for scholars in the last few years. This is partly due to its impact in contemporary media ecosystems, and its influence in political, social, cultural, and commercial behaviors around the world. Meanwhile, some segments of the population continue to be marginalized by sociotechnical configurations that perpetuate structures of dominance in the digital sphere and on social media platforms. This is the case of immigrants, who often face diverse digital, symbolic, and physical borders that neglect their voice and agency. Thus, the present study aims to explore the creative practices of immigrant tiktokers who have achieved a significant following on this platform. Using a case study approach, we explore four immigrant creator profiles with a following of 17,000 to 500,000 through in-depth interviews and a multimodal content analysis of 252 of their videos to delve into their platformed practices on TikTok. The participants are Latin American immigrant creators living in the US and Spain, identified as part of a larger study on the uses of TikTok by Latinx immigrants in these two countries exploring 53 immigrant creator profiles with more than 10,000 followers. Their practices related to algorithmic (in)visibility, and their unfolding identities including their digital, creative, political, activist, cultural, and national personas are noteworthy, and suggest unique pathways to reclaim agency through social media influence and construct multi-dimensional microcelebrity identities beyond migratory status.
\end{abstract}

\section{Keywords}

algorithm; identity; immigration; influencer; online persona; social media; TikTok; visibility

Issue

This article is part of the issue "New Narratives for New Consumers: Influencers and the Millennial and Centennial Generations" edited by Luis M. Romero-Rodríguez (Rey Juan Carlos University), Santiago Tejedor (Autonomous University of Barcelona), and Inmaculada Berlanga (International University of La Rioja).

(C) 2022 by the author(s); licensee Cogitatio (Lisbon, Portugal). This article is licensed under a Creative Commons Attribution 4.0 International License (CC BY).

\section{Introduction}

Internet research has traditionally focused on microcelebrity phenomena anchored in the Global North, which have shaped and framed our understanding of the modes of popularity that are native to online contexts. This has been observed by internet scholars who have approached this issue by emphasizing diverse microcelebrity cases in understudied regions and minority groups (Abidin, 2019; Abidin \& Brown, 2019; Semati \&
Zambon, 2021). Meanwhile, the digital practices of immigrants have traditionally been studied in terms of their unique integration and adaptation needs (Alencar, 2020), as well as their self-representations and archiving practices (Leurs, 2017), emphasizing their unique vulnerabilities to datafication and categorization by private and state actors within their receiving societies (Witteborn, 2021). Thus, their agency and uniqueness as influencers within their own communities and beyond has been largely overlooked by research in media and migration 
as well as internet research, with the few exceptions mentioned before. The present study attempts to bridge this gap by highlighting the role of Latinx immigrants in Spain and the US who have reached a significant following on TikTok, to assess the ways in which they achieve a position of influence and negotiate their own identities within the algorithmic (in)visibility enabled by the platform.

For this, we start with an overview of previous scholarship on the subject, considering the lens of internet microcelebrity (Abidin, 2018; Marwick, 2013; Senft, 2013), the dimensions of the online persona (Moore et al., 2017) and a constructivist perspective of identity (Hall, 2019). We then explore the negotiation with platform policies and politics (Gillespie, 2010, 2018) and algorithmic visibility (Bishop, 2019; Bucher, 2012). Media and migration scholarship will also be instrumental to understand the approaches and motivations of immigrants to engage in content creation (Leurs, 2017) and the possible opportunities of niche internet celebrity and (in)visibility strategies that reflect their agency within the platform. We then move to describe the research process with a focus on the appropriateness of the narrative case study approach to delve into the vast diversity among Latinx immigrant tiktokers. This enables us to delve into the main objective of our study which is to explore how their creative practices and life experiences shape their microcelebrity identities and strategies for algorithmic (in)visibility. The results provide insights about their multidimensional online personas, including their platformed strategies to present controversial political content, their creative approaches to moderation, and the ways in which their content models the "correct" ways to be an immigrant and take action in their own unique microcelebrity styles.

\section{Literature Review}

\subsection{TikTok in the Social Media Ecosystem}

TikTok is a social media platform owned by the Chinese company ByteDance that merged with Musical.ly in 2018 after ByteDance purchased it and incorporated it to the existing TikTok platform (Anderson, 2020). The social media app has grown exponentially to become the 7th largest with 689 million active users accessing every month as of the first quarter of 2021 (Mohsin, 2021).

The unique affordances of TikTok are relevant to the study of influencers and content creators due to the singularities of this platform in terms of visibility and mimesis (Abidin, 2021; Zulli \& Zulli, 2020). It offers a sole content format (15-to-180-seconds vertical video) and a unique "For You" algorithmic wall that enables content to become highly viral regardless of the connections between users (De-Casas-Moreno et al., 2020) expanding the viralization possibilities for creators. Moreover, authors have explored the structurally mimetic nature of TikTok (Zulli \& Zulli, 2020) and the functionalities and content creation configurations it offers (Figure 1), which are relevant to understand how the platform shapes content creators' negotiations of their own (in)visibility and interactions with other tiktokers and their viewers/followers.
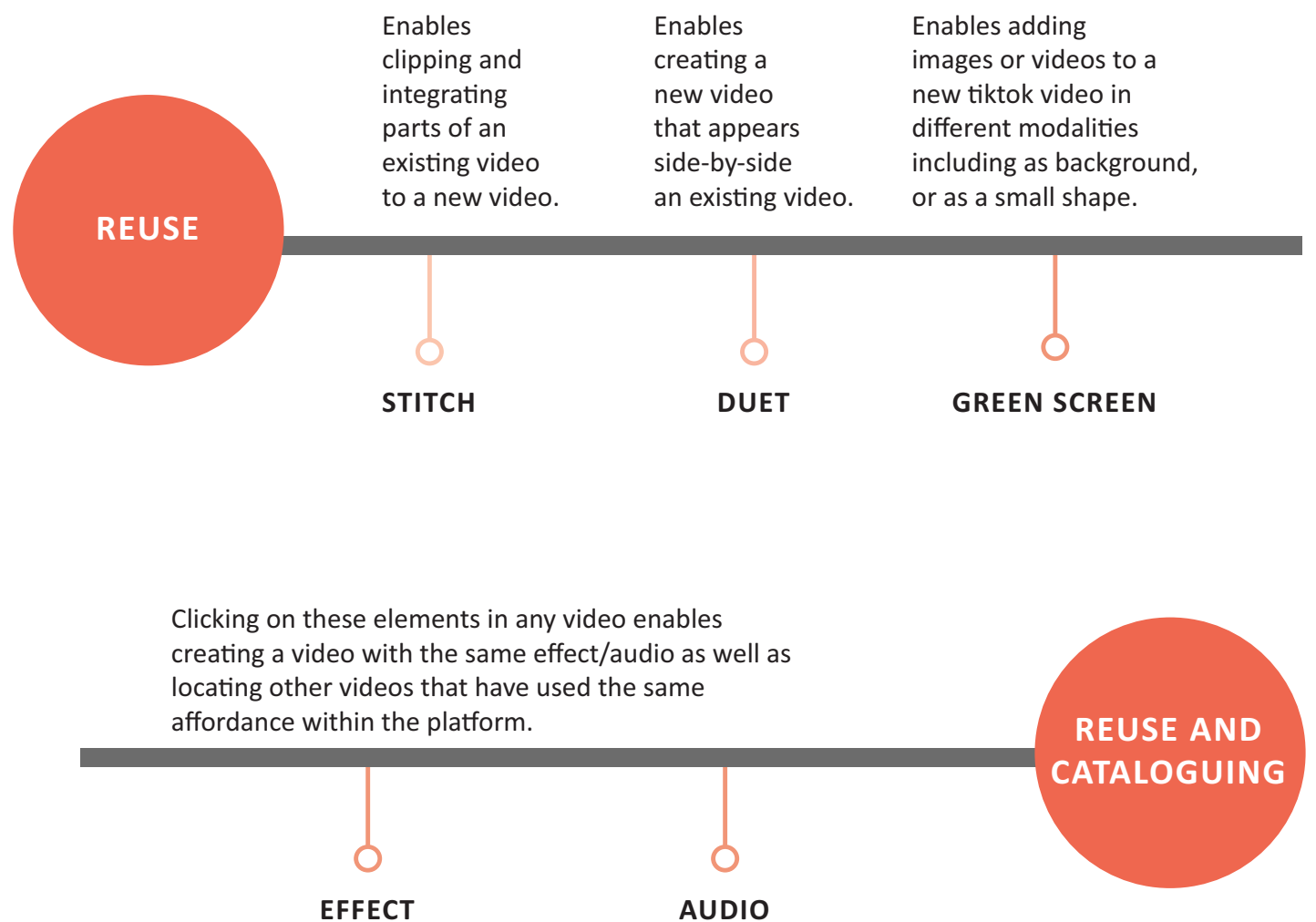

Figure 1. TikTok's content reuse and cataloguing possibilities of interest for this study (not comprehensive). 
The platform's community guidelines specifically mention a variety of protected groups in their hateful behavior moderation norms that are relevant to our study. These guidelines include speech that attacks people because of their race, ethnicity, national origin, religion, caste, and immigration status (TikTok, n.d.). However, minority creators have recently voiced their concerns, and some have even left the platform due to unequal treatment in moderation policies. A recent example includes Black creators who have attempted to flag racist accounts and content through response videos and had their content taken down by the platform due to "harassment and bullying" while the original racist posts and accounts were not deleted (Contreras \& Martinez, 2021). In response to censorship and moderation issues that disproportionally affect minority creators, TikTok has justified them as algorithmic glitches and errors. Meanwhile, minority creators have also pointed to problematic differences that allow phrases such as "I am a neo nazi" to be accepted and "Supporting Black voices" to be flagged as inappropriate (Ohlheiser, 2021). This aligns with previous literature on systemic algorithmic oppression issues for the Black community in search engines (Noble, 2018) and the ways in which new technologies perpetuate offline inequalities through biased code (Benjamin, 2019). The problems racial and ethnic minorities face could be applicable to immigrants, who are often members of these minority groups, while the hybrid human-algorithmic moderation model of social media platforms such as TikTok lends itself to the analysis of moderation (in)justice issues and the ways in which content creators negotiate their own visibility with these systems.

Moreover, TikTok is a mobile app, where content creation possibilities are available mainly through its mobile version. This is relevant, as research on media and migration has suggested that mobile connectivity provides immigrants with access to information of interest, content creation, and archiving possibilities.

\subsection{Immigrant Identities, Online Personas, and Social Media Practices}

In the present article we take a social constructivist approach to identity as a trait that is not static but shaped and changed through a process of negotiation within the contexts where the individual exists (Hall, 2019). These identities develop beyond their traditional connotations-such as religion, gender, race, and ethnicity - to include online identities shaped by their platformed actions and behaviors (Senft, 2013). In the case of internet microcelebrities, some aspects of their identity are shaped through strategic self-branding (Marwick, 2013). In this case, TikTok functions as a digital environment where creators position themselves in relation to their mediated contexts and stated connections on and offline, as portrayed in their content and in our conversations with them.
In this case, Moore's et al. (2017) online persona lens provides a multidimensional framework to understanding these behaviors and strategies as they occur in online spaces through five dimensions:

1. The public persona (which is shaped by the shift towards an increasingly public exposure and visibility) is often a sharper and perfected version of the self that follows established conventions of correct publicness in the face of a growing audience;

2. The mediatized persona refers to the media formats and skills that shape today's digital content creation and sharing, in a constant negotiation with the platform and online communities, resulting in a set of media identities shaped by interactions and meaning making between audiences and creator;

3. The performative persona emphasizes actions and content creation practices that reflect the different aspects of the creator's identity such as gender, interests, profession, stances, among others, and this is done in a way that combines the authentic and fictitious self, in a complex blend of various aspects that are part of identity;

4. The collective persona reflects the individual as a node that connects with various publics of different sizes and characteristics;

5. The value dimension refers to the intentions behind the creation of specific personas and the shift between different persona registers and selfpresentations to cater to diverse publics, intentions, and the achievement of goals such as prestige, fame, among others.

The role of social media in identity formation and online persona presentation through its archiving and placemaking possibilities has been solidified in media and migration literature. Thus, the possibilities of social media to collect migratory experiences and their implications for identities and belongings in different immigration stages are reflected in studies related to the narration of life stories, from migratory journeys (Labayen \& Gutierrez, 2021) to the practices of self-representation as devices to establish deservingness (Nikunen, 2019). Moreover, others have focused on the affinity and affective connection facilitated by social media (Marino, 2015; Marlowe et al., 2017) and the aspirations and achievements enabled by mobile social media (Witteborn, 2015, 2019). The political immigrant identities established through social media content for agency and rights claims (Leurs, 2017) and their negotiation with real and symbolic borders (Chouliaraki \& Georgiou, 2019) have also been explored. In the case of the Latin American community in the US specifically, researchers have focused on the ways in which social media enables simple and multi-present connectivity among families, who often share online content and digital materials (Bodinger-deUriarte \& Valgeirsson, 2019). These 
perspectives are relevant to contextualize the functions of social media content creation by immigrants with those of immigrant microcelebrities to assess how these evolve once creators become more popular.

An important consideration for the exploration of identity is the diversity among Latinx immigrant populations in terms of national origins and migratory experiences, as well as political and ideological stances, which in many cases will shape their public-facing affiliations and online personas. In this sense both countries boast large and diverse Latin American immigrant populations due to aspects such as culture, geography, legislation, and financial opportunity, that motivate them to choose these two destinations (Connor \& Massey, 2010). The political heterogeneity of the Latinx community is also relevant, as recent research suggests that immigration issues are not prioritized equally across Hispanics in the US, and Trump has attracted a relevant following among this group (Galbraith \& Callister, 2020).

It is noteworthy that throughout this article we use the terms Latin American and Latinx to refer to the specific creators we targeted. In the case of "Latin American," the term refers to people from countries in the region spanning 19 countries in North and South America who speak Romance languages, mainly Spanish and Portuguese (Bodenheimer, 2019). In the case of Latinx, it is a non-gendered term that goes beyond the common language dimension to comprise diverse ethnicities and cultures across various national origins that is in constant flux (Bodinger-deUriarte \& Valgeirsson, 2019).

\subsection{Diversity in Internet Microcelebrity}

The current celebrity ecosystem has been described as one where a range of networked, transnational publics navigate and negotiate ideologically diverse provocations, and where a range of identities related to race, nationality, and class are performed (Semati \& Zambon, 2021). Similarly, internet microcelebrity has been conceptualized based on strategic practices and processes (Abidin, 2018) where metrics like the number of followers are less important than the feeling of authenticity and interactivity conveyed (Marwick, 2013). Thus, in these processes and strategic actions, the relationship established with followers is critical (Abidin, 2018) as well as the negotiation of visibility and popularity with the platform (Gillespie, 2010, 2018) and the algorithm (Bishop, 2019; Bucher, 2012). In terms of specific celebrity profiles applicable to the present study, Abidin (2019) defined minority celebrities as online creators who shape their brand and popularity by harnessing their status as part of a marginalized group and one where different layers of identity and celebrity converge.

Additional scholarship of interest has explored examples of microcelebrity with a global, culturally diverse, and minority perspective (Abidin \& Brown, 2019); the instrumentalization of celebrity immigrants to promote linguistic integration in Germany (Zambon, 2021); and the analysis of linguistic and cultural practices of Chinese diasporic and rural microinfluencers residing abroad (Zhang \& Zhao, 2020; Zhang, 2020). The scarcity of literature on immigrant influencers reflects a gap that may provide some alternatives to the well-documented fact that immigrants become voiceless in their own narratives and subject to symbolic bordering (Chouliaraki \& Georgiou, 2019).

It is important to note that for the purposes of the present study, we use the umbrella term "immigrant" to refer to content creators who self-identify as foreigners living abroad. It is worth noting that this term does not have a legal definition and is often used interchangeably with terms such as "migrant" to refer to a vast diversity of mobile and foreign populations. Thus, the term "immigrant" is preferred instead of the term "migrant" because it is more effective in validating a more permanent status within the country of residence, and one that is unlikely to change, as observed by Anderson and Blinder (2019).

\section{Methods}

To capture the evolving nature of Latinx immigrant microcelebrity with a focus on identity and algorithmic (in)visibility practices, we take a narrative case study approach to four exemplary profiles within this niche TikTok ecosystem. The case study involves the multimodal content and discourse analysis of 252 TikTok videos and in-depth interviews with four immigrant creators. This study does not intend to enable generalization but to understand specific, diverse examples (Flyvbjerg, 2006) that illustrate the variation that exists among Latin American immigrant influencers and their voices, and to reflect on the importance of emphasizing the diversity within seemingly homogeneous minority groups. The objective of the study is to explore how their creative practices and life experiences shape their microcelebrity identities and strategies for (in)visibility. We do this within the framework of Hall's (2019) view of identity as shaped and constructed through life experiences and social, contextual negotiation and considering Senft's (2013) definition of digital identities, which are molded through online actions and behaviors. The research procedure is described in Figure 2.

\subsection{Sampling, Data Collection, and Analysis}

The sampling process was carried out as part of a larger research project through the initial analysis of 53 profiles of Latin American immigrant creators on TikTok residing in the US and Spain, with more than 10,000 followers in each country, as this is the threshold where creators begin receiving payments from TikTok (Cariaga, 2021). Between August 2020 and January 2021, we observed videos in these profiles daily and took field notes. The resulting selection criteria included: adherence to topics related to immigration, periodic growth in terms of followers and overall likes, and posting con- 


\begin{tabular}{|c|c|c|c|c|c|}
\hline PREP & \multicolumn{2}{|c|}{ SAMPLING } & \multicolumn{2}{|c|}{ DATA COLLECTION } & ANALYSIS \\
\hline $\begin{array}{l}\text { RESEARCH } \\
\text { ACCOUNTS }\end{array}$ & $\begin{array}{l}\text { IDENTIFICATION } \\
\text { OF CONTENT }\end{array}$ & $\begin{array}{l}\text { ASSESSMENT OF } \\
\text { MIGRANT STATUS }\end{array}$ & SCRAPING & INTERVIEWS & ATLAS.TI \\
\hline $\begin{array}{l}\text { We created two } \\
\text { research accounts to } \\
\text { observe immigrant } \\
\text { creator profiles in } \\
\text { Spain and the US } \\
\text { separately between } \\
\text { August } 2020 \text { and } \\
\text { January } 2021 .\end{array}$ & $\begin{array}{l}\text { We searched for } \\
\text { content using } \\
\text { hashtags of interest, } \\
\text { which included } \\
\text { \#inmigrante } \\
\text { \#migrante } \\
\text { \#emigrante to identify } \\
\text { content by Hispanic } \\
\text { immigrants. } \\
\text { We identified a } \\
\text { significant number of } \\
\text { videos and profiles in } \\
\text { this process. } \\
\text { We assessed the } \\
\text { cooccurring hashtags } \\
\text { within these videos to } \\
\text { identify other } \\
\text { immigrant status and } \\
\text { residence in the US } \\
\text { and Spain such as } \\
\text { \#latinaespaña or } \\
\text { \#venezolanaenusa } \\
\text { and by clicking on } \\
\text { these hashtags, } \\
\text { identified new } \\
\text { videos of interest. }\end{array}$ & $\begin{array}{l}\text { By observing and } \\
\text { exploring each of } \\
\text { the creators' } \\
\text { profiles we } \\
\text { assessed the status } \\
\text { of the creator as } \\
\text { a Latin American } \\
\text { national residing in } \\
\text { the US or Spain. } \\
\text { When this } \\
\text { assessment could } \\
\text { not be made, we } \\
\text { excluded such } \\
\text { content. } \\
\text { We identified } \\
53 \text { profiles with } \\
\text { more than 10K } \\
\text { followers and } \\
\text { observed them for } \\
\text { several months to } \\
\text { assess whether } \\
\text { they create } \\
\text { content regularly. }\end{array}$ & $\begin{array}{l}\text { Scraped the last } \\
65 \text { videos and } \\
\text { metadata from } \\
\text { each of the four } \\
\text { accounts selected } \\
\text { using a Python } \\
\text { script, after } \\
\text { excluding } \\
\text { duplicates and } \\
\text { eliminated videos, } \\
\text { the final sample } \\
\text { includes } 252 \\
\text { videos from } \\
4 \text { accounts. }\end{array}$ & $\begin{array}{l}\text { We conducted } \\
\text { in-depth } \\
\text { interviews with } \\
4 \text { creators to } \\
\text { assess their } \\
\text { motivations, } \\
\text { identities and } \\
\text { practices on } \\
\text { the platform. } \\
\text { We chose a } \\
\text { sample of } \\
10 \text { videos to } \\
\text { collaboratively } \\
\text { analyze the } \\
\text { intentions of the } \\
\text { participants } \\
\text { in creating } \\
\text { such content. }\end{array}$ & $\begin{array}{l}\text { We prepared the } \\
\text { data and uploaded } \\
\text { to Atlas.ti. The } \\
\text { analysis of interview } \\
\text { transcripts and } \\
\text { TikTok video was } \\
\text { conducted } \\
\text { separately. }\end{array}$ \\
\hline
\end{tabular}

Figure 2. Research procedure.

tent regularly. It is worth noting the challenge of contacting TikTok creators because of the platform's limitations in terms of private messaging. After failed attempts, we identified alternative contact forms including email addresses or profiles on Instagram and Facebook and contacted them through those profiles. This excluded creators who did not have alternative contact options. Using this strategy, we contacted a total of 23 creators (11 in the US and 12 in Spain) who aligned with the selection criteria and got responses from five, with a final sample of four profiles chosen purposively (Palys, 2008) as depicted in Table 1.

In-depth interviews were conducted in Spanish between March and May 2021 with a semi-structured script derived from the initial observation and field notes from 53 profiles. The interviews covered 5 topics: general data, self-described identities, use of TikTok affordances and functionalities, strategies for algorithmic visibility, and relationship with followers. The complete list of topics is included as supplementary material. During the interviews, participants provided informed consent for us to scrape their videos and to use their profile information and content in the present study. Due to the possible risks for participants and considering the ethical implications of exposing immigrant creators, we made the decision to exclude identifying information from the results and use pseudonyms that exemplify their real names without exposing them. The figures and hashtag examples have been modified in some cases to avoid the identification of the creator but to enable us to illustrate our argument. The analysis of data was carried out using an iterative process of analysis whereby we selected a subset of 10 videos to illustrate practices of interest during the interviews and included participants' perspectives and rationale for content creation. This complemented the subsequent critical multimodal content and discourse analysis of their videos (see Table 2).

Scraping was done on 11 June, 2021 using the unofficial API wrapper for TikTok in Python (Teather, 2021). This API enabled us to download each profile's last 65 videos

Table 1. Profiles included in the sample.

\begin{tabular}{llllllll}
\hline Pseudonym & Followers & Likes & Other profiles & Gender & Country & Posting Periodicity & Sampled videos \\
\hline @ICE_hunter & $502 \mathrm{~K}$ & $3.9 \mathrm{M}$ & IG, YT & Male & US & Daily or more & 63 \\
@Emy_blondie & $56.6 \mathrm{~K}$ & $446.7 \mathrm{~K}$ & IG, YT & Female & US & Daily or more & 65 \\
@PetehonduranDJ & $57.3 \mathrm{~K}$ & $485.3 \mathrm{~K}$ & IG, FB & Male & Spain & Every 3 days & 63 \\
@JanSuarez & $17.5 \mathrm{~K}$ & $188.3 \mathrm{~K}$ & IG, FB & Female & Spain & Every 2 days & 61 \\
\hline
\end{tabular}

Notes: Number of followers and likes as of September 24, 2021. Total sample consists of 252 videos. Posting regularity is approximate and in some cases, there are periods with no posts due to content moderation and suspension by the platform. 
Table 2. Code groups for TikTok video content analysis.

\begin{tabular}{ll}
\hline Code Group & Definition \\
\hline MLTMD & Multimodal linguistic elements (e.g, emoji/hashtags/text) \\
TKTK & Specific TikTok affordances and creative configurations (e.g, duet/stitch/audio/effects) \\
IDENT & $\begin{array}{l}\text { Creative elements and narratives that suggest specific national, cultural, political, ideological, creative, } \\
\text { and digital identities. }\end{array}$ \\
BRAND & Personal branding elements. \\
FOLWERS & Promotion of interactions with followers. \\
PLATF & Content creation strategies to negotiate platform visibility and content moderation. \\
\hline
\end{tabular}

and related metadata by writing and executing a Python script. Videos and related metadata were uploaded to Atlas.Ti and analyzed using inductively derived code groups related to phenomena of interest in relation to the research objective and the conversations with creators (see Table 2).

\section{Findings}

In the next sections we will describe each microcelebrity profile and their use of TikTok affordances as relevant to understand some of the commonalities among those who have achieved a significant number of followers, as well as the intricate identities of these creators. Emphasis is placed in the intersections with their microcelebrity identities and algorithmic visibility strategies.

\subsection{Fearless Political Activism for TikTok Visibility}

ICEhunter defines himself as a Latin American activist in favor of human rights. His brand name is present as embedded text signatures and hashtags which illustrate his identity as a creator. His content reflects a combination of footage of himself and others following and facing
ICE (Immigration and Customs Enforcement) agents and the promotion of human rights for immigrants regardless of their status (Figure 3). He provides practical information for immigrants facing deportation, emphasizing the strategies of ICE officers. His experience as an undocumented immigrant for 22 years motivates and shapes his content. His visibility strategies in the use of multimodal elements are relevant as part of his identifying creative practices.

For this creator, losing his account on Facebook severely impacted his current approach to moderation. He describes his experience:

I started on TikTok in December, after my Facebook was cancelled...as part of Facebook's mass closure of MAGA, neo-Nazi and white supremacist accounts. The algorithm took my activist and personal accounts for good because I was confronting them and exposing them.

This personal anecdote with Facebook's algorithmic moderation resembles Black creators' claims of unequal treatment on TikTok, where their content flagging racist videos is deleted (Contreras \& Martinez, 2021; Ohlheiser,
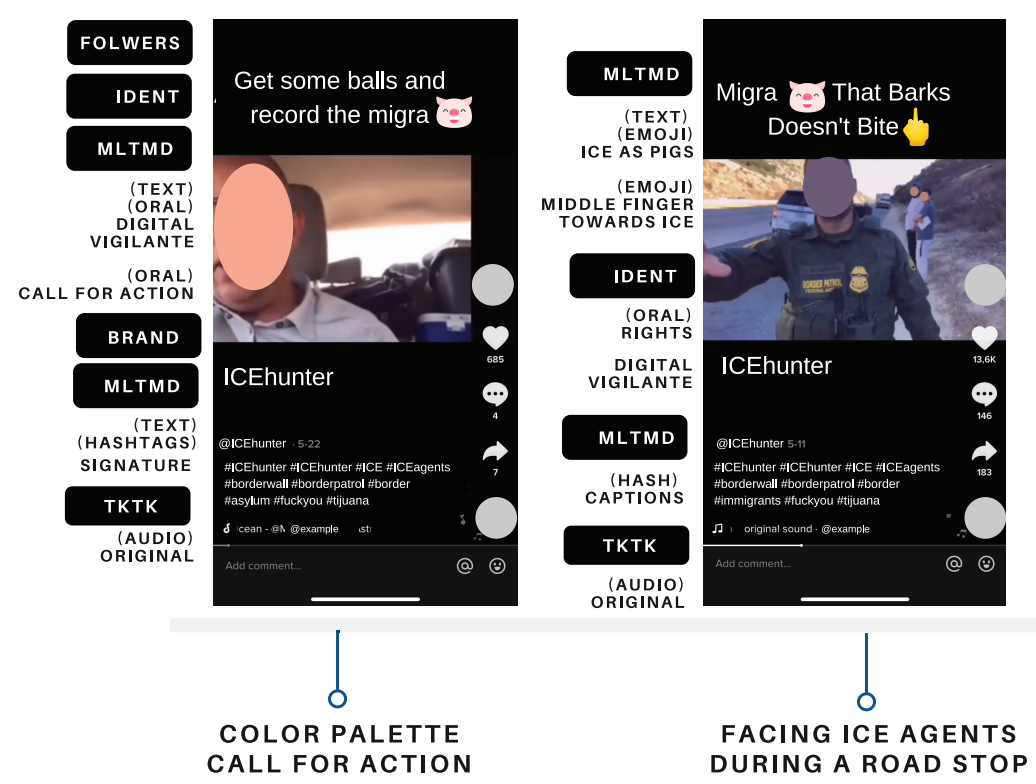

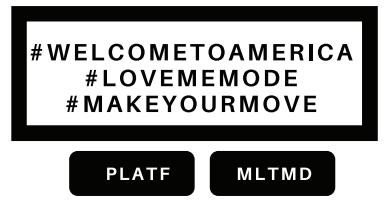

HASHBAITING
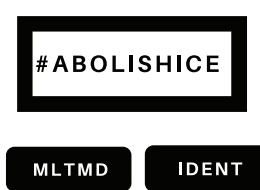

STANCE TAKING

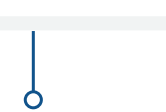

HASHTAGS
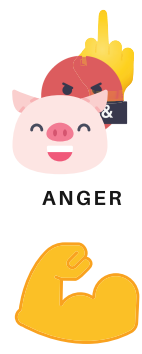

STRENGTH

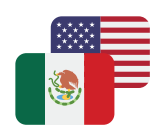

LOCATION/

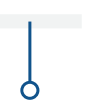

EMOJI

Figure 3. ICEhunter's use of multimodal elements and TikTok configurations. 
2021). He describes this experience as "Jail" and when asked about TikTok's moderation algorithm he describes it as "completely unpredictable." Due to this unpredictability, ICEhunter was unable to describe the sort of content that gets flagged because he usually doesn't understand the reason, but he explained his negotiation with the platform:

When a video gets flagged, I erase it, and then edit it, change the editing cuts, or add effects such as snow falling or colors, which confuses the algorithm, and I post it again. If it gets flagged again, I take it down. If TikTok determines that it doesn't want to see the video, I don't post it again and I do something different.

This reflects his current self-moderating approach of trial-and-error, in line with Gillespie's (2018) description of platform content removal and account suspension impacting present and future speech by forcing creators to move to other platforms and become wary of the guidelines and the need to adapt their content to abide by the rules. It also illustrates his management of his mediatized persona (Moore et al., 2017) by skillfully modifying the format and presentation of his message to find a way across platform moderation. This also supports previous research about immigrants' use of social media to present different identities through content creation (Leurs, 2017), in this case curating content to avoid deletion. It is noteworthy that his approach to content moderation does not include mentioning eliminated or flagged content in his videos, as opposed to @Emy_Blondie, as we will explain later.

Moreover, for increased viewership he reported including "eye-catching, dramatic headlines" as illustrated in Figure 3 with the headline "get some balls and record the migra." He also describes in his strategy identifying trending hashtags that fit his content topics through TikTok searches to foster algorithmic visibility. His content reflects the use of hashtags created for the launch of the movie \#WelcometoAmerica to label his content supporting immigration. These actions reflect a refined strategy to be picked up by the For You page and expand his reach in line with previous research (Abidin, 2021; Zulli \& Zulli, 2020). We have coined this practice "hashbaiting" due to its similarities with clickbaiting. Hashbaiting is defined as the use of trending hashtags that connotationally relate to the hashtagged content but refer to mediated events that are thematically different. This practice enables a creator to take advantage of highly popular campaigns without sacrificing thematic coherence, while targeting his intended audience and prospective new publics through cooccurring hashtags that combine profile branding (\#ICEhunter; MLTMD/BRAND) and stance taking (\#abolishICE) that reflects his political identity as part of his self-branding practices (Marwick, 2013) and is in line with previous research on hashtag branding functions (Page, 2012).

These strategic, multimodal practices illustrate a careful understanding of the sociotechnical nature of TikTok visibility and its algorithm. His use of the black and white color palette and visual cues (emoji) are part of his visual identity and are strategically deployed to maintain the attention of new For You viewers beyond the one-time viewership opportunity afforded by TikTok. Figure 4 reflects his use of the duet function to highlight other tiktokers while emphasizing his TikTok creator self as described in his interview by (a) expressing his support for deportees and showing ICE agents visiting people at home; (b) highlighting instances of language-based discrimination and highlighting the linguistic rights of people in the US while featuring the voice of the original

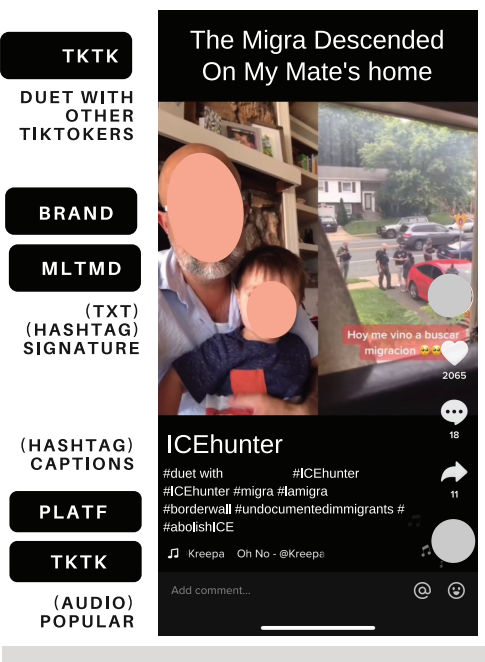

d

DUET TO SUPPORT AND HIGHLIGHT DEPORTEES
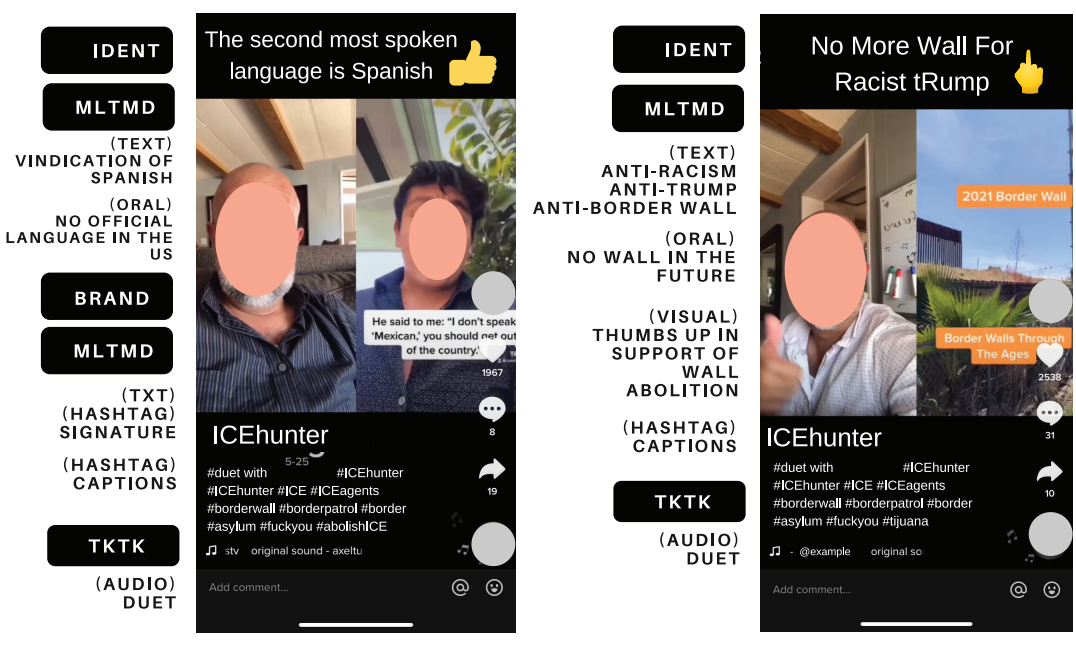

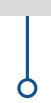

DUET IN SUPPORT OF LINGUISTIC RIGHTS

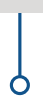

DUET FOR STANCE TAKING

Figure 4. ICEhunter's use of the duet function, multimodal elements, and TikTok configurations. 
creator; and (c) by stating his political stance in relation to Trump and the border wall as racist and oppressive symbols of the current US policies towards immigration.

His account features content that is mainly in Spanish, although we found some English terms, pronunciations, and hashtags, reflecting his dual linguistic profile as a long-term Latin American immigrant in the US. When asked about his followers and the nature of his interactions with them, he said:

Ninety-eight percent of the people who watch the videos are grateful because many have no idea about the level of racism in this country....Most people didn't know that their rights are guaranteed by the Constitution...even if you're undocumented. Occasionally white supremacists threaten to kill me, to the point where I must go to the Sheriff's office with screenshots of images of AR-15s pointed at me.

Thus, his relationships with supporters, opponents, other tiktokers, and the algorithm shape the performative nature of his digital vigilante persona (Gabdulhakov, 2019) by systematically involving his viewers in diverse ways. This ranges from prompting action in their own context as seen in Figure 3, where he provides detailed instructions on the best ways to face ICE agents and calls for followers to submit this content to him to post in videos that often follow his model of rights-based interaction with ICE agents. By following and facing ICE agents after a road stop of two immigrants and establishing his right to record and be around with questions and statements such as "why did you stop them?," "you don't have the right to touch me," or "I have a right to record" he provides an illustrated how-to guide. In many cases, his vigilante self converges with his mediatized persona (Moore et al., 2017), which is reflected in his cre- ative practices and anonymization of information about the immigrants portrayed on videos submitted to him. We could argue that, by sharing these anonymized thirdparty videos, he effectively becomes the visible face of the collective experiences of immigrants in the US, which often depict systematic oppression and unlawful prosecution, which are prevalent themes in his content. This also highlights his awareness of the threats and opportunities afforded by algorithmic visibility (Bucher, 2012), with an understanding of the unique implications of this visibility for vulnerable populations (Witteborn, 2015, 2021). He expresses no fear of continuing to create and share this content regardless of the online or in-person attacks he receives because "I see this as key work; I need to leave a better country for my son."

\subsection{Unexpected Politics and Unwilling Co-Creation}

Emy_blondie self-identifies as a conservative immigrant from Mexico who has lived in the US for 10 years and in her own words "aims to promote the right of Latinos in the US to think differently." She states that she does not want people to think like her, but her aim is to provide an alternative political perspective. She fits within Lewis' (2020) description of "reactionary microcelebrity" due to her opposition to social justice movements and mainstream media, especially Hispanic media outlets in the US. Her content ranges from sarcastic political stances to fierce responses to criticism. She routinely positions herself politically through the involvement of tiktokers across the political spectrum using the "stitch" function-which enables creators to take a portion of an existing video and attach their content to it-as well as the "respond to comment" and "green screen" functionalities in a practice we have called "unwilling co-creation" (see Figure 5).

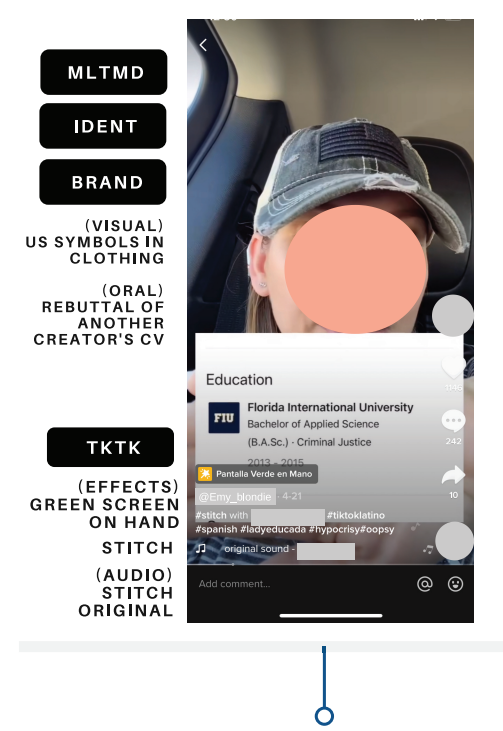

UNWILLING CO-CREATION
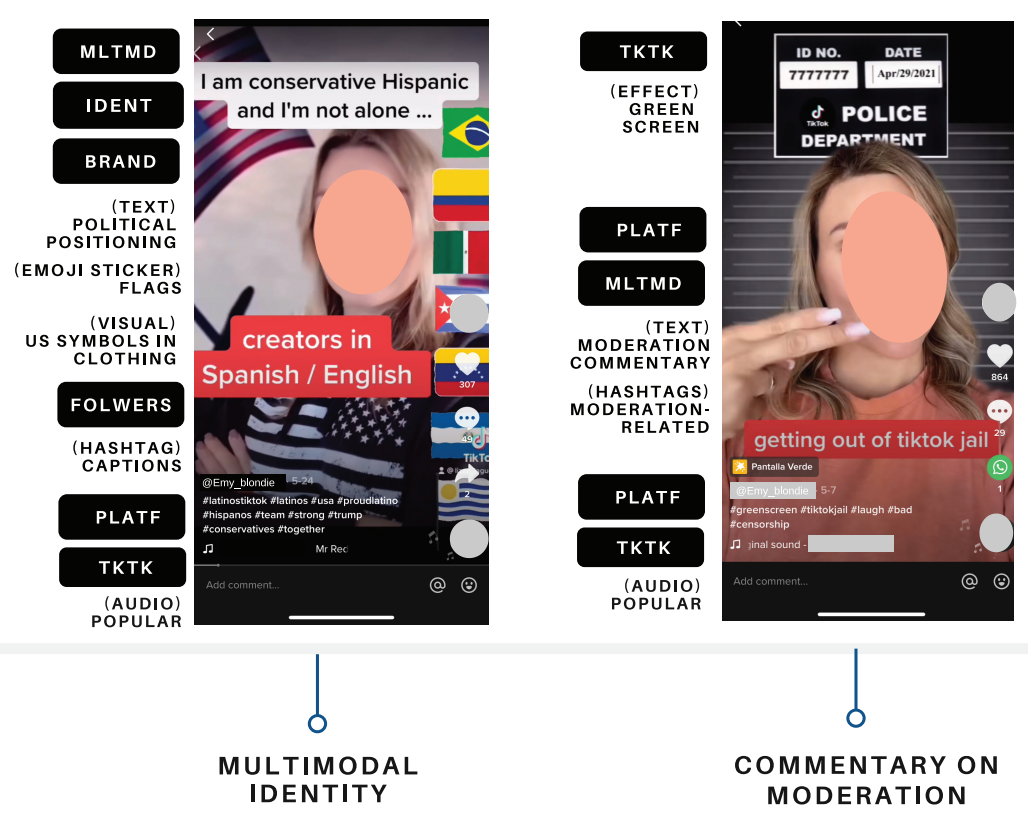

Figure 5. Emy_blondie's use of multimodal elements and TikTok configurations. 
We define unwilling co-creation as the use of platform affordances to coopt another person's content (including videos, comments, or audio) using the editing possibilities afforded by the platform, in an aim to criticize the original creator or solidify a stance (see Figure 5). This could be considered a TikTok-enabled sub-genre of "response videos," a YouTube genre that involves a creator from one political side editing a video by a creator from the opposing political side to simulate a debate (Lewis et al., 2021). TikTok is a particularly fertile ground for this kind of practice due to its mimetic structure that facilitates imitation, reuse, and resignification of existing content (Zulli \& Zulli, 2020). Thus, Emy_blondie's unwilling co-creation practices include viewers and other tiktokers whose content enables her to contextualize and validate her various identities, but especially her political stance, often without regard for the (mis)representation of an issue or a person. It is possible to suggest that this also constitutes an attempt at visibility through controversy (Gillespie, 2018). In contrast with ICEhunter, her content is mainly in English, and she routinely argues for "language as integration" in line with previous research on immigrant celebrities as icons for "proper" integration (Zambon, 2021, p. 216). During her interview, she reflects on her shift to English content:

When I just started on TikTok, I posted a message in Spanish criticizing BLM protesters saying "I don't agree that they are using the Mexican flag when they are destroying and burning places." The next day I received messages threatening to kill me and my family...just for saying that I didn't agree.....I decided to use English because...a lot of young people who grew up in the US don't speak Spanish...and they don't have very good information....and I have found a lot of support from the American community.

This episode profoundly shaped her public persona (Moore et al., 2017) in response to attacks by her Spanish-speaking community and the support of the native US community on TikTok. In this sense, her multilayered persona includes performative dimensions of her Latin American immigrant background, conservative politics, and an emphasis on patriotism towards the US, which suggests an extreme attempt at establishing herself as a deserving immigrant through a display of cultural and national values (Chouliaraki \& Georgiou, 2019; Nikunen, 2019).

The inclusion of other like-minded Latinx tiktokers in her content suggests a unique form of digitally enabled claims of belonging (Marino, 2015; Marlowe et al., 2017) with the added layer of political affinity and the construction of common enemies that exist beyond their common national and cultural identities. Moreover, this community of like-minded creators engage in collectively generated content to suggest that moderation policies disproportionally affect Hispanic conservatives and place part of the blame on individuals who flag their content.
She describes TikTok's moderation practices as "censorship" and akin to ICEhunter mentions "TikTok jail" as a period when content is obscured, or the account is suspended. In her videos (Figure 5), she discusses this perceived suppression in her self-described sarcastic, humorous tone, illustrating an overlap of her mediatized, performative, and public personas (Moore et al., 2017). Her approach to moderation is sternly different to ICEhunter's as she uses her videos to highlight periods of suspension and "obscuring" of her content while he adapts his content quietly and attempts to abide by the platform's moderation rules. In this regard, Gillespie (2018) reminds us that social media are privately owned and therefore entitled to limit users' speech, albeit with implications that are problematic in a highly mediatized and platformed information ecosystem.

\subsection{Fearless Empowerment and Motivation From the Margins}

JanSuarez is a Honduran immigrant who moved to Spain three years ago. Her content centers on the promotion of rights, empowerment, and motivation for fellow immigrants and other TikTok users. She creates empathetic content that stems from her self-described difficulties and migratory experiences. Her videos display a mixture of humor, nostalgia, affirmations for resilience and nods to her multilayered identities, as can be seen in Figure 6 .

JanSuarez considers viewer engagement as central in her success as a creator. She attempts to make her content light and positive while highlighting a balanced perspective on her life as a foreigner in Spain. Her content displays fewer consistent branding elements in comparison to the rest of the creators, which supports Abidin's (2021) argument that TikTok's algorithmic configuration has meant that creators rely on video-based popularity rather than cohesive profiles. Her platformed cultural and national identities are shaped by the use of emoji flags, hashtags, punta music and occasionally through clothing to convey her Honduran background as can be seen in Figure 6 . She regularly posts content about immigrant rights. Her content goes from serious statements, to anger towards immigrant abuse and light humor imitating trendy TikTok content to touch upon controversial issues such as entering as a tourist and staying in Spain as shown in Figure 6. When asked about this content she replied:

The simple fact of being a human being means you have rights, you must know them. Being in the country with no papers does not mean you have to become a slave....We must open people's eyes to the fact that they have many rights....For example, they should receive respect from their boss, from their coworkers, they cannot be physically and verbally abused.

Her stance on immigrant rights reflects and influences much of the videos she produces and the way in which 

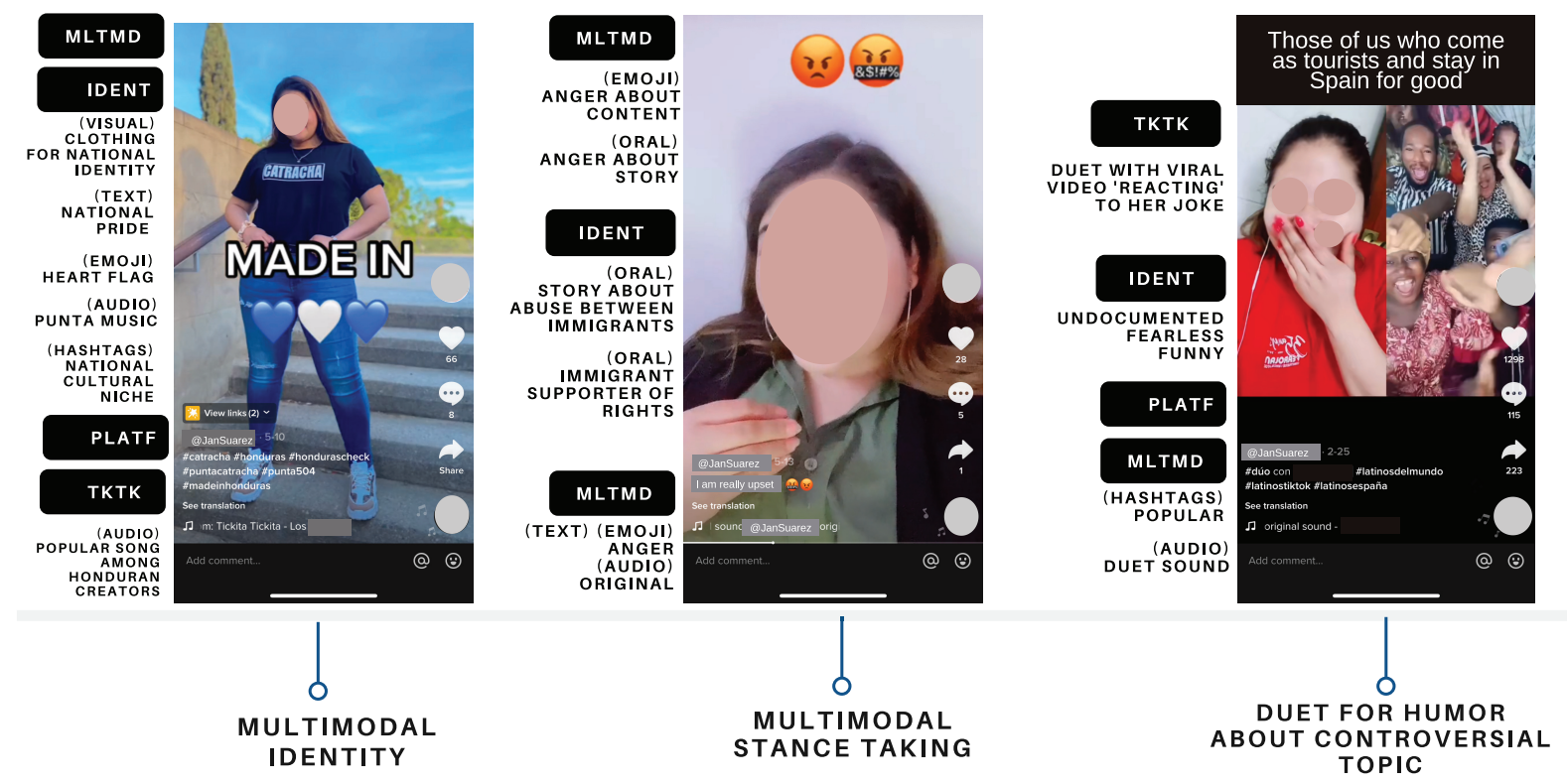

Figure 6. JanSuarez's multimodal identity and persona-related practices.

her migratory experience shapes her identity as a creator highlights the socially constructed (Hall, 2019) and evolving nature of online identities, through her creative actions and decisions (Senft, 2013). On the one hand, the mediatized and value dimensions of her online persona (Moore et al., 2017) are portrayed in the creation of original audio tracks of motivation, empowerment, and self-esteem to be reused by others. This reflects her understanding of the mimetic nature of the platform (Zulli \& Zulli, 2020) as well as the role of audio memes as vehicles for storytelling and connection between creators and viewers (Abidin, 2021).

Figure 7 illustrates her labels of this type of audio track using the hashtag \#voiceeffects and in some cases including embedded text and captions that read "use this audio track." The deployment of multimodal elements to promote interaction beyond likes and views reflects an insider knowledge of algorithmic visibility within this specific platform (Bishop, 2019; Bucher, 2012). Some of these audio tracks stem from personal experiences that are applicable to the immigrant community:

Every migrant has his or her own story....It is very difficult to start anew in a new country, new languages, new cultures...far away from your family. I know I am going to make it; I am going to achieve everything I set out to do (@JenSuarez's audio track)

It is noteworthy that-like ICEhunter-she reports no fear of retaliation or hate by followers due to content
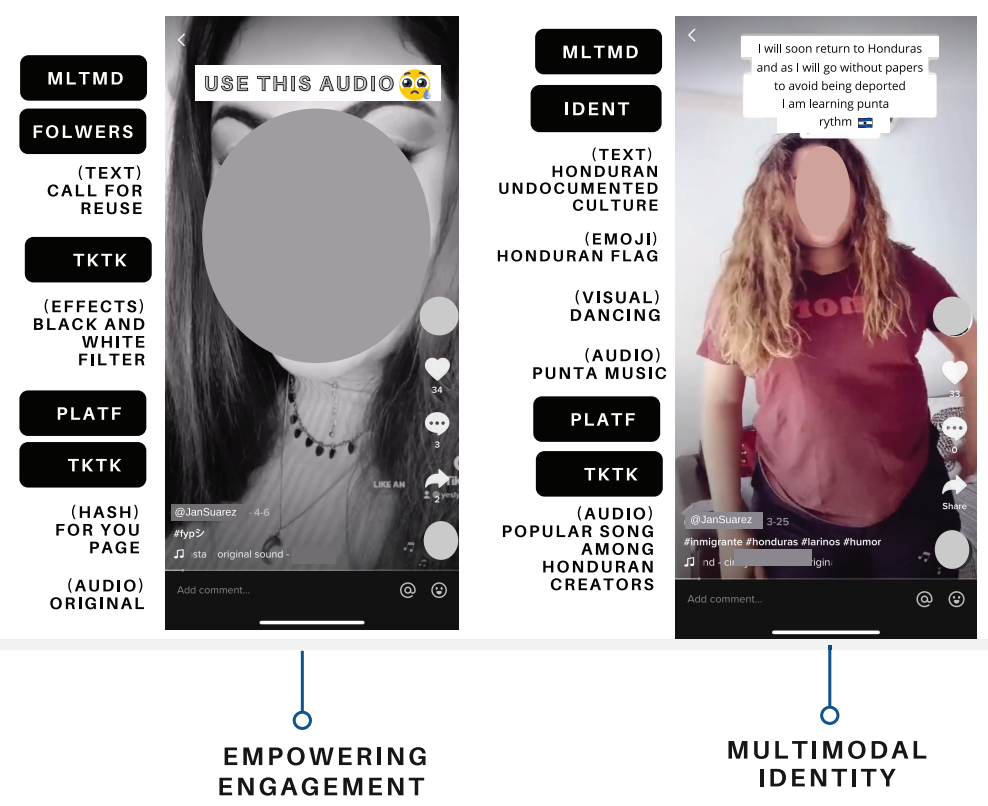

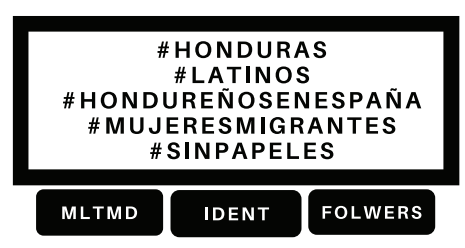

IDENTITY/AUDIENCE

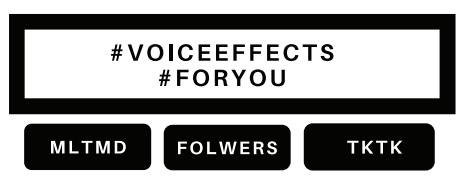

VISIBILITY/INTERACTION

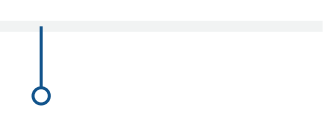

HASHTAGS

Figure 7. JanSuarez's multimodal and visibility practices. 
that touches on issues such as undocumented immigration. She constitutes an unlikely example considering the fear many immigrants experience when creating online content due to symbolic and digital bordering (Chouliaraki \& Georgiou, 2019) and in line with the idea of social media content creation as a claim for communication rights and political positioning (Leurs, 2017). She also notes that none of her content has been filtered or eliminated by the platform, suggesting that she is able to balance controversial topics with humor and an acquired familiarity with TikTok's algorithmic visibility. This seems to have allowed her to develop a more "platform friendly" political style that enables her to bypass moderation and flagging while presenting information that may be contentious for some users.

\subsection{Crossmedia Cultural and National Pride}

PeteHonduranDJ self-describes as a proud Honduran, a journalist who has lived in Spain for the past 16 years but has never lost his connection with his country of birth. He explains that he understands that Spanish media prefers to hire native journalists, so he has mostly worked in media aimed at the Latin American public. He works as a DJ in a radio station based in Barcelona geared to Honduran nationals and uses TikTok to expand his reach. His content features advice for love and life, often related to immigration and being Honduran as well as messages of support for fellow Latin Americans.

PeteHonduranDJ features the most comprehensive branding strategy among participating creators. It is shaped by what he calls the "character" he becomes when he wears his glasses and clothing that reflects his Honduran identity or his public persona (Moore et al., 2017). His use of branded clothing and punta music is similar to JanSuarez's but much more consistent and strategic. Figure 8 illustrates his logo and slogan "Honduras in the house 504" and objects that visually reflect his branding. His crossmedia strategy combines visual props for TikTok and audio branding at the end of all his TikTok videos "PeteHonduranDJ....I'm gone...hahahaha." This is a creative way to ensure reuses of his audio include his signature among this platform's imitation publics (Zulli \& Zulli, 2020) in line with his concern related to audio reuse enabled by the platform "what sometimes annoys me is that...they use the audio and don't give you the credits."

His entire creative strategy and personal brand are in stern contradiction with previous research that suggests that immigrants attempt to reflect their integration through allegiance to the receiving country's values, culture, and patriotism (Nikunen, 2019) which could be due to his relative privilege in comparison with other immigrants and his professional status, working in niche media targeted at Latin American audiences.

He discusses various issues related to immigration such as advice for undocumented immigrants who want to travel by plane and his take on linguistic integration by Honduran immigrants:

When you come to these countries, the United States or Spain, if you want to speak like a Spaniard...speak however you want. Now my advice is that, when you are with fellow Hondurans...you should try to speak like a Catracho [word Hondurans use to refer to themselves].

His position of influence makes this especially relevant as he advices and models a specific way to migrate without losing one's national/cultural identities. His perception

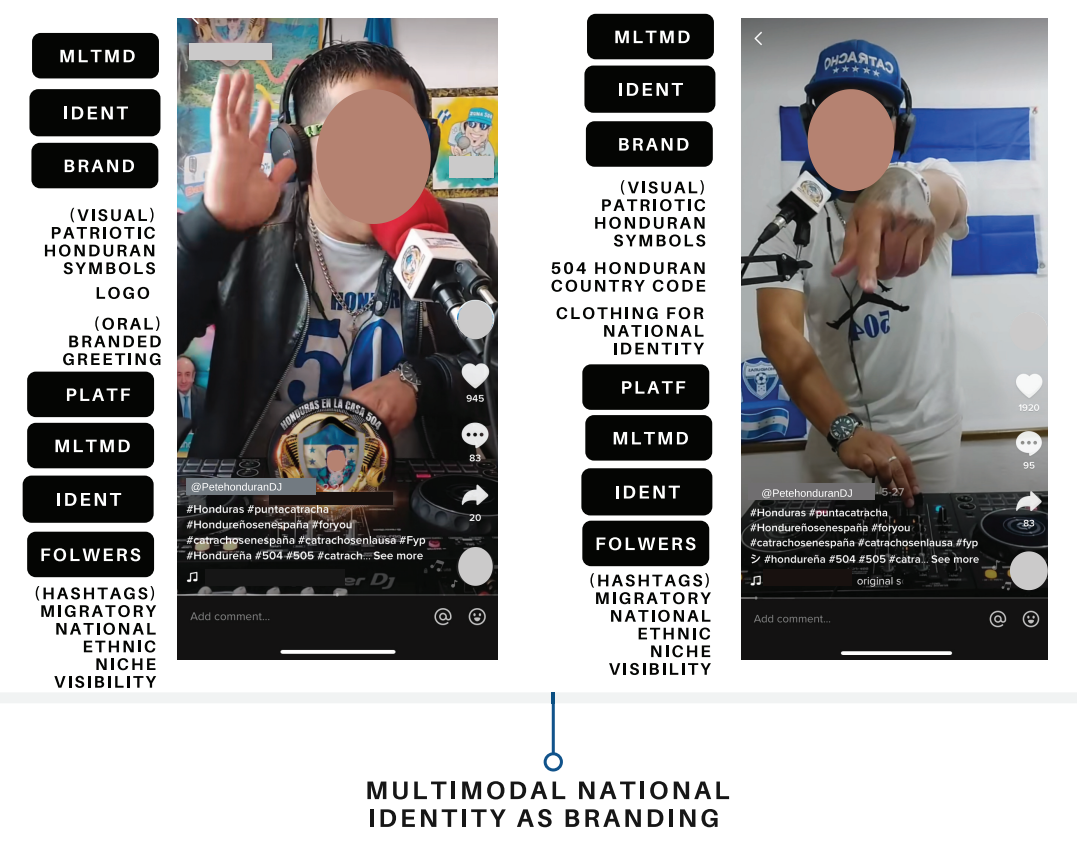

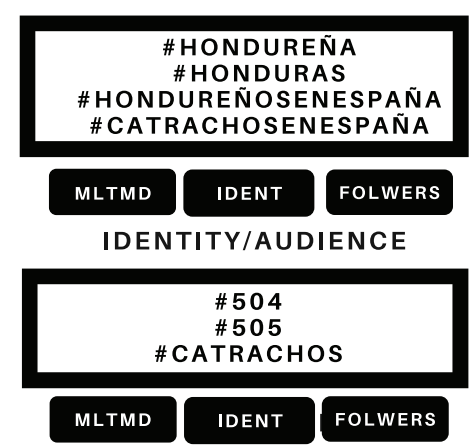

NICHE PUBLICS

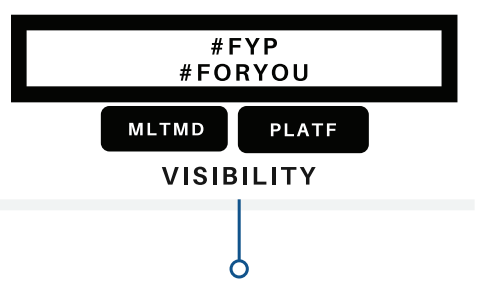

HASHTAGS

Figure 8. PeteHonduranDJ's multimodal branding and hashtag uses. 
of identity seems to negate multiplicity, in favor of one "authentic" self that should align with one's national background and native language/dialect rather than linguistic and cultural adaptations to become integrated in the country of residence. This reflects a stern opposition to Emy_blondie, who takes an extreme stance about the need to culturally and linguistically adapt in order to belong.

He negotiates his algorithmic visibility using culturally relevant hashtags and the remix and parody of trending audio tracks. He uses his knowledge of musical mixing to create parodic content that fits his creative, humorous TikTok persona while including slight nods to his own culture and nationality. This aligns with Zulli and Zulli's (2020) description of the partial imitation of popular audio tracks as a strategy to increase visibility on TikTok but with the added layer of culturally relevant creative elements within mainstream trending audio tracks.

\section{Conclusions}

The multilayered profiles and creative practices of these tiktokers reflect complex and diverse identities and online personas that exist among Latin American immigrants in both countries. We argue that these smaller niche communities of followers enable the emergence of microinfluencers whose life trajectory, identity, and politics often diverge from what is expected, simultaneously exemplifying the diverse profiles that exist among Latinx immigrants who may engage in rights claims (Leurs, 2017) to unexpected ideas of ideological freedom and seemingly contradictory identities that have been studied in terms of political participation by Hispanics in the US (Galbraith \& Callister, 2020).

All the creators reflected the goal to reach as many people as possible with statements that reflect a stance on issues, claims for rights, and motivating affirmations that illustrate the presence of an immigrant identity, reflected by a focus on culturally relevant life experiences and different approaches to political engagement. The ways in which these creators understand and harness TikTok's possibilities for co-creation shape their behavior-based microcelebrity personas (Abidin, 2018; Moore et al., 2017; Senft, 2013) but also build upon their immigrant experiences as identity-shaping narratives. Their creative strategies position them in relation to political issues such as the border wall or linguistic integration, while platformed practices such as hashbaiting and unwilling co-creation reflect some of the algorithmic visibility and identity construction strategies enabled by the platform and harnessed by these creators.

Thus, algorithmic (in)visibility actions by these creators are threefold. First, they reflect an understanding of the unique technical nature of the TikTok algorithm using hashtags, effects, remixed audio, and visually impactful content. Second, they promote specific actions to viewers that may range from likes and shares to co-creation enabled by the platform. Third, they show different approaches to content moderation that enable them to present contentious political content and engage with their followers in unique ways. For this, they often rely on personal traits to establish affinity with their followers, based on their immigrant experience, linguistic preferences, political leaning, or national/cultural selves. Their approach to moderation, censorship, and relevant politics illustrates a multitude of ways in which they navigate real and perceived injustice as outsiders in their respective societies, and within TikTok. It also reflects their distinct perspectives of integration and immigrant rights, shaped by their own migratory experience and their position of (relative) privilege.

This study included a small sample that provides an initial overview of diverse microinfluencers and may benefit from further studies that delve into the larger community of immigrant creators and their algorithmic and creative practices.

\section{Acknowledgments}

This work was supported by Alfamed (Euro-American Research Network), under Grant $R+D+I$ Project (2019-2021), entitled Youtubers and Intagrammers: Media competence in emerging prosumers, with code RTI2018-093303-B-I00, financed by the Spanish Ministry of Science, Innovation and Universities and the European Regional Development Fund (ERDF), and the R+D-i Project (2020-2022), entitled Instagrammers and youtubers for the transmedia empowerment of Andalusian citizens. The media competence of instatubers, with code P18-RT-756, financed by the Andalusian Regional Government in the 2018 call (Andalusian Research, Development and Innovation Plan, 2020) and the European Regional Development Fund (ERDF). The authors would like to thank the reviewers for their thoughtful and helpful comments, which have significantly improved the article.

\section{Conflict of Interests}

The authors declare no conflict of interests.

\section{Supplementary Material}

Supplementary material for this article is available online in the format provided by the author (unedited).

\section{References}

Abidin, C. (2018). Internet celebrity: Understanding fame online. Emerald Publishing.

Abidin, C. (2019). Minahs and minority celebrity: Parody YouTube influencers and minority politics in Singapore. Celebrity Studies, 12(4), 598-617. https://doi. org/10.1080/19392397.2019.1698816

Abidin, C. (2021). Mapping internet celebrity on TikTok: Exploring attention economies and visibility labours. 
Cultural Science Journal, 12(1), 77-103. https://doi. org/10.5334/csci.140

Abidin, C., \& Brown, L. M. (Eds.). (2019). Microcelebrity around the globe: Approaches to cultures of internet fame. Emerald Publishing.

Alencar, A. (2020). Mobile communication and refugees: An analytical review of academic literature. Sociology Compass, 14(8), Article e12802. https://doi.org/ 10.1111/soc4.12802

Anderson, B., \& Blinder, S. (2019). Who counts as migrant? Definitions and their consequences. The Migration Observatory at University of Oxford. https://bit.ly/2WB4xjS

Anderson, K. E. (2020). Getting acquainted with social networks and apps: It is time to talk about TikTok. Library Hi Tech News, 37(4), 7-12. https://doi.org/ 10.1108/LHTN-01-2020-0001

Benjamin, R. (2019). Race after technology. Polity.

Bishop, S. (2019). Managing visibility on YouTube through algorithmic gossip. New Media \& Society, 21(11/12), 2589-2606. https://doi.org/10.1177/ 1461444819854731

Bodenheimer, R. (2019, July 28). What Is Latin America? Definition and list of countries. ThoughtCo. https:// bit.ly/3Aocg3h

Bodinger-deUriarte, C., \& Valgeirsson, G. (2019). La familia in digital space and face-to-face: Millennial Latinx navigating, customizing, and reconfiguring familismo. In C. Bodinger-deUriarte (Ed.), Interfacing ourselves: Living in the digital age (pp. 107-124). Routledge.

Bucher, T. (2012). Want to be on the top? Algorithmic power and the threat of invisibility on Facebook. New Media \& Society, 14(7), 1164-1180. https://doi.org/ $10.1177 / 1461444812440159$

Cariaga, V. (2021, April 26). How many TikTok followers do you need to quit your day job? New calculator tells you. GOBankingRates. https://bit.ly/3wZzBWJ

Chouliaraki, L., \& Georgiou, M. (2019). The digital border: Mobility beyond territorial and symbolic divides. European Journal of Communication, 34(6), 594-605. https://doi.org/10.1177/0267323119886147

Connor, P., \& Massey, D. S. (2010). Economic outcomes among Latino migrants to Spain and the United States: Differences by source region and legal status. International Migration Review, 44(4), 802-829. https://doi.org/10.1111/j.1747-7379.2010.00826.x

Contreras, B., \& Martinez, M. (2021, September 16). Fed up with TikTok: Black creators are moving on. Los Angeles Times. https://lat.ms/3Eo3NjO

De-Casas-Moreno, P., Jaramillo-Dent, D., \& VizcaínoVerdú, A. (2020). TikTok y el nuevo reto para las marcas [TikTok and the new challenge for brands]. In J. Gil-Quintana \& B. Castillo-Abdul (Eds.), Influenciar para construir las sombras de la realidad: Youtubers e influencers en la era postdigital [Influence to construct the shadows of reality: Youtubers and influencers in the postdigital era] (pp. 215-235).
Sindéresis.

Flyvbjerg, B. (2006). Five misunderstandings about casestudy research. Qualitative Inquiry, 12(2), 219-245. https://doi.org/10.1177/1077800405284363

Gabdulhakov, R. (2019). In the bullseye of vigilantes: Mediated vulnerabilities of Kyrgyz labour migrants in Russia. Media and Communication, 7(2), 230-241. https://doi.org/10.17645/mac.v7i2.1927

Galbraith, Q., \& Callister, A. (2020). Why would Hispanics vote for Trump? Explaining the controversy of the 2016 Election. Hispanic Journal of Behavioral Sciences, 42(1), 77-94. https://doi.org/ $10.1177 / 0739986319899738$

Gillespie, T. (2010). The politics of "platforms." New Media \& Society, 12(3), 347-364. https://doi.org/ $10.1177 / 1461444809342738$

Gillespie, T. (2018). Custodians of the Internet: Platforms, content moderation, and the hidden decisions that shape social media. Yale University Press.

Hall, S. (2019). Essential essays: Identity and diaspora (Vol. 2). Duke University Press.

Labayen, M. F., \& Gutierrez, I. (2021). Digital placemaking as survival tactics: Sub-Saharan migrants' videos at the Moroccan-Spanish border. Convergence, 27(3). https://doi.org/10.1177/1354856520982974

Leurs, K. (2017). Communication rights from the margins: Politicising young refugees' smartphone pocket archives. International Communication Gazette, 79(6/7), 674-698. https://doi.org/10.1177/ 1748048517727182

Lewis, R. (2020). "This is what the news won't show you": YouTube creators and the reactionary politics of micro-celebrity. Television \& New Media, 21(2), 201-217. https://doi.org/10.1177/152747641 9879919

Lewis, R., Marwick, A. E., \& Partin, W. C. (2021). "We dissect stupidity and respond to it": Response videos and networked harassment on YouTube. American Behavioral Scientist, 65(5), 735-756. https://doi.org/ 10.1177/0002764221989781

Marino, S. (2015). Making space, making place: Digital togetherness and the redefinition of migrant identities online. Social Media + Society, 1(2), 1-9. https:// doi.org/10.1177/2056305115622479

Marlowe, J. M., Bartley, A., \& Collins, F. (2017). Digital belongings: The intersections of social cohesion, connectivity, and digital media. Ethnicities, 17(1), 85-102. https://doi.org/10.1177/1468796816654 174

Marwick, A. (2013). Status update: Celebrity publicity and branding in the social media age. Yale University Press.

Mohsin, M. (2021, February 16). 10 TikTok statistics that you need to know in 2021. Oberlo. https://bit.ly/ 2VbKiFA

Moore, C., Barbour, K., \& Lee, K. (2017). Five dimensions of online persona. Persona Studies, 3(1), 1-11. https://search.informit.org/doi/10.3316/informit. 
956460438195724

Nikunen, K. (2019). Once a refugee: Selfie activism, visualized citizenship, and the space of appearance. Popular Communication, 17(2), 154-170. https://doi.org/ 10.1080/15405702.2018.1527336

Noble, S. U. (2018). Algorithms of oppression: How search engines reinforce racism. New York University Press.

Ohlheiser, A. (2021, July 12). Welcome to TikTok's endless cycle of censorship and mistakes. MIT Technology Review. https://bit.ly/3knDp08

Page, R. (2012). The linguistics of self-branding and micro-celebrity in Twitter: The role of hashtags. Discourse \& Communication, 6(2), 181-201. https://doi. org/10.1177/1750481312437441

Palys, T. (2008). Purposive sampling. In L. M. Given (Ed.), The SAGE encyclopedia of qualitative research methods (Vol. 2, pp. 697-698). SAGE.

Semati, M., \& Zambon, K. (2021). The global politics of celebrity. Popular Communication, 19(3), 159-163. https://doi.org/10.1080/15405702.2021.1922690

Senft, T. (2013). Microcelebrity and the branded self. In J. Hartley, J. Burgess, \& A. Bruns (Eds.), A companion to new media dynamics (pp. 346-354). Wiley-Blackwell.

Teather, D. (2021). TikTok API [Computer software]. GitHub. https://bit.ly/3iret7g

TikTok. (n.d.). Community guidelines: TikTok. https://bit. ly/3Cqi2lo

Witteborn, S. (2015). Becoming (im)perceptible: Forced migrants and virtual practice. Journal of Refugee Studies, 28(3), 350-367.

Witteborn, S. (2019). The digital gift and aspirational mobility. International Journal of Cultural Studies, 22(6), 754-769. https://doi.org/10.1177/1367877 919831020

Witteborn, S. (2021). Digital placemaking and the datafication of forced migrants. Convergence, 27(3), 637-648. https://doi.org/10.1177/1354856521100 3876

Zambon, K. (2021). Celebrity migrants and the racialized logic of integration in Germany. Popular Communication, 19(3), 207-221. https://doi.org/10.1080/ 15405702.2021 .1892692

Zhang, L. T., \& Zhao, S. (2020). Diaspora microinfluencers and Covid-19 communication on social media: The case of Chinese-speaking YouTube vloggers. Multilingua, 39(5), 553-563. https://doi.org/ 10.1515/multi-2020-0099

Zhang, X. (2020). The rural video influencers in China: On the new edge of urbanization [Master thesis, Cornell University]. Cornell University Library. https://bit.ly/ 36fMnp2

Zulli, D., \& Zulli, D. J. (2020). Extending the Internet meme: Conceptualizing technological mimesis and imitation publics on the TikTok platform. New Media \& Society. Advance online publication. https://doi. org/10.1177/1461444820983603

\section{About the Authors}

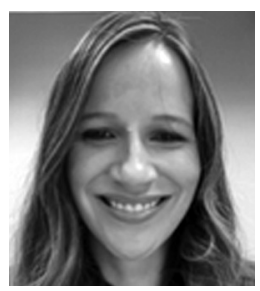

Daniela Jaramillo-Dent is a research fellow and doctoral candidate in communication at the University of Huelva and Erasmus University Rotterdam (joint PhD). Her research focuses on the mediated (self)representations of immigration on social media platforms. She is part of research networks and projects at the national, Latin American, and European levels researching social media platforms and content creators. Her research explores migratory narratives of othering, belonging, identity, and minority celebrity on TikTok and Instagram.

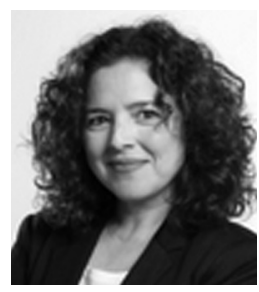

Paloma Contreras-Pulido (PhD in education) is a journalist and social educator. She is also an associate professor in the Department of Educational Technologies at the Faculty of Education (International University of La Rioja), as well as a professor for the UHU-UNIA's master's degree in communication and audiovisual education and in the Interuniversity Doctorate in communication. She is a researcher of the Agora Group (HUM-648), specialized in media literacy specializing in social exclusion. Scientific reviewer of the journal Comunicar and member of the Alfamed Network (Euro-American InterUniversity Network for Research on Media Literacy for Citizenship).

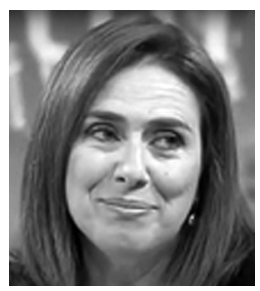

Amor Pérez-Rodríguez is an associate professor at the University of Huelva. Her research and publications focus on the field of Educommunication, the development of media competence, and its consequent literacy (media literacy), as well as new narratives in digital contexts. She is associate editor for the scientific journal Comunicar Q1 in JCR. 